\title{
Comparison of Characteristics According to Reflux Type in Patients With Laryngopharyngeal Reflux
}

\author{
Jun Seok Lee · Ah Ra Jung · Jung Min Park · Myung Jin Park · Young Chan Lee · Young-Gyu Eun \\ Department of Otolaryngology-Head and Neck Surgery, Kyung Hee University School of Medicine, Seoul, Korea
}

Objectives. To analyze laryngopharyngeal reflux (LPR) as an acidic, nonacidic, or mixed type according to 24-hour multichannel intraluminal impedance (MII) $\mathrm{pH}$ monitoring and the clinical characteristics of each type.

Methods. Ninety patients were prospectively enrolled in this study. All patients underwent 24-hour MII pH monitoring as a diagnostic tool. Eighty-three patients were diagnosed with LPR. The patients were classified into three groups according to the $\mathrm{pH}$ of the hypopharyngeal probe: the acid reflux group, nonacid reflux group, and mixed reflux group. Subjective symptoms and objective findings were evaluated based on patients' responses to the Short Form 12 Survey (SF-12), LPR health-related quality of life (LPR-HRQOL), reflux symptom index, and reflux finding score.

Results. The results of each group were compared. As a result, 34 patients were classified into the nonacid reflux group and 49 into the mixed reflux group. There were no patients classified as having acid reflux alone. There was no significant difference between the two groups when comparing the reflux symptom index, reflux finding score, LPR-HRQOL, or the mental component score of the SF-12. However, the physical component score of the SF-12 was higher in the nonacid reflux group $(P=0.018)$. The DeMeester composite score $(P=0.015)$ and total number of LPR events $(P=0.001)$ were lower in the nonacid reflux group than in the mixed reflux group.

Conclusion. In conclusion, no LPR patient had only acid reflux. The nonacid reflux LPR patients showed similar clinical characteristics and findings compared to the mixed reflux group, but exhibited significantly fewer LPR episodes.

Keywords. Laryngopharyngeal Reflux; Reflux Type; 24-Hour Multichannel Intraluminal Impedance pH Monitoring

\section{INTRODUCTION}

The symptoms of laryngopharyngeal reflux (LPR) disease result from gastric contents entering the laryngopharyngeal area. LPR is associated with extraesophageal symptoms such as dysphagia, hoarseness, chronic cough, globus sensation, throat clearing, and laryngeal spasm. LPR patients typically experience long-term discomfort due to the chronic and intermittent nature of the symptoms. Also, persistent frequent exposure of the laryngopharynx to gastric reflux can lead to laryngeal erythema, vocal fold

\footnotetext{
- Received May 18, 2017

Revised July 31, 2017

Accepted September 6, 2017

- Corresponding author: Young-Gyu Eun

Department of Otolaryngology-Head and Neck Surgery, Kyung Hee

University School of Medicine, 26 Kyungheedae-ro, Dongdaemun-gu,

Seoul 02447, Korea

Tel: +82-2-958-8474, Fax: +82-2-958-8470

E-mail: ygeun@hanmail.net
}

edema, subglottic edema, postglottic hypertrophy, ventricular obliteration, endolaryngeal mucus, and granuloma formation [1].

The diagnosis of LPR is traditionally based on the presence of laryngeal symptoms and laryngoscopic findings. However, the sensitivity and specificity of laryngologic findings are poor, and abnormal findings of the larynx are identified in up to $86 \%$ of healthy, asymptomatic subjects [2]. Another effective diagnostic method for LPR is dual-channel 24-hour pH monitoring. However, the pharyngeal $\mathrm{pH}$ probe is poorly responsive due to the alkaline environment within the proximal digestive tract. Also, neutralization of distal acid events by saliva influences the sensitivity of the tool [3]. Therefore, there is a need for more accurate and objective testing of LPR. While 24-hour multichannel intraluminal impedance (MII) $\mathrm{pH}$ monitoring was introduced 10 years previously, the instrument is primarily used for the detection of gastroesophageal reflux (GER). It enables the characterization of reflux episodes in liquid, gas, or mixed forms; hence, both acidic and nonacidic reflux episodes can be detected. As it

Copyright $@ 2018$ by Korean Society of Otorhinolaryngology-Head and Neck Surgery

This is an open-access article distributed under the terms of the Creative Commons Attribution Non-Commercial License (http://creativecommons.org/licenses/by-nc/4.0)

which permits unrestricted non-commercial use, distribution, and reproduction in any medium, provided the original work is properly cited. 
allows for a more accurate evaluation of the chronology of reflux episodes and laryngeal symptoms, the application of 24hour MII pH monitoring is steadily increasing [4].

Most patients with suspected LPR are treated empirically with proton pump inhibitors (PPIs) and lifestyle modifications. PPIs are potent drugs that inhibit the reflux of gastric contents [5]; however, it has been reported [6,7] that $20 \%-30 \%$ of patients treated with PPIs are unresponsive to these drugs. The reason for the refractory response may be the nonacidic nature of the reflux episodes [8]. Therefore, the authors of this study focused on the characteristics of nonacidic reflux LPR. By classifying LPR as an acid, nonacid, or mixed type according to 24hour MII pH monitoring, we analyzed and compared the clinical characteristics of these types of LPR.

\section{MATERIALS AND METHODS}

\section{Subjects}

This was prospective observational study. We evaluated patients who visited the Department of Otolaryngology of Kyung Hee University Medical Center from August 2014 to August 2015. All were first-time patients who were evaluated for symptoms that were clinically indicative of LPR, for which they underwent a fundamental otolaryngologic examination including video laryngoscopy (SOPRO-COMEG, Tuttlingen, Germany). Patients who met any of the following criteria were excluded from this study: unwilling to participate, previous use of medication for reflux disease, history of surgery for reflux or peptic ulcer disease, history of chronic wasting disease or malignancy, and younger than 18 years of age. Ultimately, 90 patients underwent 24-hour MII pH monitoring (ZepHr Impedance/pH Reflux Monitoring System; Sandhill Scientific Inc., Highlands Ranch, CO, USA) as a diagnostic tool. A prospective clinical study was performed based on patient data after approval from Institutional Review Board of Kyung Hee University Hospital (IRB No. KMC IRB 1432-01) and performed in accordance with the principles of the Declaration of Helsinki. Informed consent was obtained from all participants included in this study.

\section{Physical examination and questionnaires}

Patients who complained of more than one qualifying symptom

\section{H I G H L I G H T S}

- Acid, nonacid, and mixed types of laryngopharyngeal reflux (LPR) were determined in 83 patients with 24-hour multichannel intraluminal impedance $\mathrm{pH}$ monitoring.

- No LPR patients had acid reflux.

- Clinical characteristics between patients with nonacid and mixed LPR did not differ. at their first clinic visit underwent laryngeal examination using video laryngoscopy in the clinical laboratory. These symptoms included hoarseness, chronic cough, globus sensation, laryngeal spasm, chronic throat clearing, and dysphagia. Belafsky's reflux finding score (RFS) [9] was recorded based on pathologic laryngeal signs such as hyperemia, vocal fold edema, pseudosulcus, posterior commissural hypertrophy, ventricular obliteration, diffuse laryngeal edema, granuloma formation, and thick endolaryngeal mucus. The RFS ranged from 0 to 26 , with a higher score indicating a deteriorated laryngeal condition, and 0 indicating a normal condition.

Subjective symptoms and quality of life (QOL) were evaluated based on patient responses to three surveys: Short Form 12 Survey (SF-12) [10], the LPR health-related quality of life (LPRHRQOL) [11], and the reflux symptom index (RSI) [12]. The results of each survey were compared with the results of 24-hour MII $\mathrm{pH}$ monitoring. The SF-12 is a useful quality measurement tool to evaluate HRQOL. It is comprised of eight different categories of physical functioning, role-physical, bodily pain, general health, vitality, social functioning, role-emotional, and mental health. Each SF-12 category is divided into two component scores: a physical component score (PCS) and a mental component score (MCS). The average agreement among the eight categories indicates the general health condition of the patient, with a higher score indicating a better health condition. The authors focused on the PCS and MCS from the SF-12.

LPR-HRQOL is a reliable and valid QOL rating scale described by Carrau et al. [11]. This method can be used to evaluate the QOL of LPR patients through a simple survey comprised of 43 questions across five categories of hoarseness, cough, throat clearing, swallowing, and the overall impact of acid reflux. The questionnaire uses a basic 7-point Likert scale for questions in four categories, while a 10-point Likert scale is used to assess the overall impact of acid reflux. A high score indicates more severe symptoms, whereas a score of 0 indicates no symptoms.

The RSI evaluates the level of symptoms and their severity through a 6-point Likert scale, which ranges from 0 to 5 . A high score indicates that patients have more severe symptoms, whereas a score of 0 indicates no symptoms. Generally, when the total score (the sum of all item scores) is greater than 10 , the LPR is considered to be severe.

\section{Twenty-four-hour MII pH monitoring test}

The dual-channel MII-pH catheter used in this study was composed of a 2.3-mm polyurethane catheter that incorporated six impedance segments and two $\mathrm{pH}$-measuring electrodes ( $\mathrm{ZepHr}$ Impedance/pH Reflux Monitoring System, Sandhill Scientific Inc.). The catheter models (ZAI-BL-54, 55, 56, Comfor-TEC Z/ $\mathrm{PH}$ single-use probe with 2.3-mm diameter; Sandhill Scientific Inc.) used were based on the patient's esophageal length. The configuration of this catheter enabled the recording of changes in intraluminal impedance at each point. Additionally, $\mathrm{pH}$ was moni- 
tored at the hypopharynx (proximal, $\mathrm{pH}$ 1) and esophagus (distal, $\mathrm{pH}$ 8). Using direct visualization, a fiberoptic scope was inserted into the nasal cavity to assist probe placement. A dual-channel MII-pH catheter was then inserted through the nose to the opposite side of the fiberscope inserted previously, and the blue visualization band was placed $1 \mathrm{~cm}$ below the proximal $\mathrm{pH}$ sensor at the proximal edge of the upper esophageal sphincter [13].

The probe was attached to an external electronic data recorder for 24 hours to monitor the esophageal $\mathrm{pH}$. It was removed the following day, and the $\mathrm{pH}$ data were downloaded for analysis (ZepHr Compact Flash Card and Recorder, Sandhill Scientific Inc.). Patients were instructed to record the time of each meal and to document the occurrence of cough, globus, heartburn, and regurgitation [14].

\section{Data analysis}

Each MII tracing was manually analyzed. A distal reflux event was defined as an episode that reached the two impedance sensors closest to the lower esophageal sphincter. An episode that reached the two impedance sensors closest to the oropharynx was defined as a proximal reflux event and was considered to be LPR in this study. These reflux events were classified as acidic if the $\mathrm{pH}$ decreased below 4 , and as nonacidic if the $\mathrm{pH}$ remained above 4 during the episode. LPR was diagnosed if a proximal reflux episode occurred more than one time. If the reflux episode had a proximal $\mathrm{pH}>4$ per every event, the patient was classified into the nonacid reflux group. Patients were placed in the acid reflux group if a proximal $\mathrm{pH}<4$ occurred per each event. If reflux episodes showed a proximal $\mathrm{pH}<4$ and $>4$ alternately for every event during the examination period, the patient was placed in the mixed reflux group.

The DeMeester composite score was based on the total index of the upright time in reflux (\%), recumbent time in reflux, total

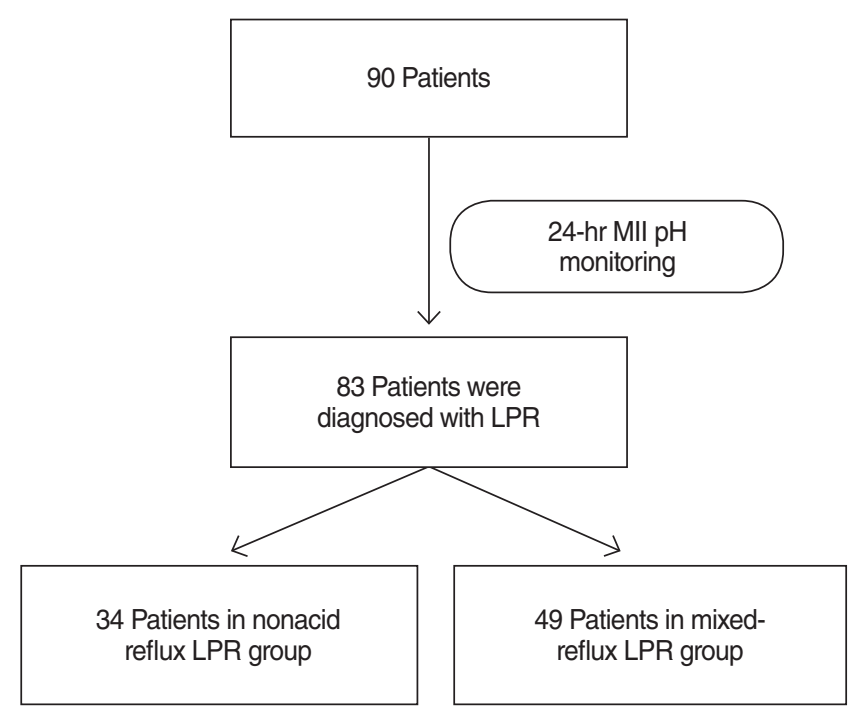

Fig. 1. Flow chart of this study. MII, multichannel intraluminal impedance; LPR, laryngopharyngeal reflux. time in reflux, episodes longer than 5 minutes, the longest episode, and total episodes. A DeMeester composite score of $<14.7$ was considered normal. To evaluate the associations between reflux and typical symptoms such as cough, globus sensation, and heartburn, we used the data of symptom episodes that patients recorded. We also compared aspects of distal reflux among the three groups.

For statistical analysis, SPSS ver. 18.0 (SPSS Inc., Chicago, IL, USA) was used to compare the RFS, RSI, SF-12, and LPRHRQOL results among the three reflux groups. Furthermore, the DeMeester composite score, total reflux events, and reflux symptom association probability were compared among the three groups to identify the characteristics of nonacidic LPR. A $P$-value $<0.05$ was considered significant.

\section{RESULTS}

Ninety patients were investigated by physical examination, surveys, and 24-hour MII $\mathrm{pH}$ monitoring under the suspicion of LPR; 83 patients $(92.2 \%)$ were consequently diagnosed with LPR (28 males and 55 females; mean age, $52.8 \pm 13.1$ years; age distribution, 19 to 80 years) (Fig. 1).

Thirty-four patients $(41.0 \%)$ were classified into the nonacid reflux LPR group, and 49 patients $(59.0 \%)$ were classified into the mixed-reflux LPR group. No patients were included in the acid reflux group after 24-hour MII $\mathrm{pH}$ monitoring. As a result, the acid reflux group was excluded from statistical analysis, and the data of the two remaining groups were compared. The analysis showed no significant differences between the two groups in relation to RSI, RFS, LPR-HRQOL, SF-12 MCS, or personal history, including accompanying disease, smoking, drinking of alcohol or coffee, and operative history although there were differences in the SF-12 PCS. The SF-12 PCS was significantly higher in the nonacid reflux LPR group $(P=0.018)$ (Table 1$)$.

The DeMeester composite scores were lower in the nonacid reflux group $(P=0.015)$, and no patients in either group showed a score $>14.7$. The total number of LPR events was lower in the

Table 1. Comparison of questionnaire and RFS findings between nonacid and mixed LPR patients

\begin{tabular}{lccc}
\hline Variable & $\begin{array}{c}\text { Nonacid group } \\
(\mathrm{n}=34)\end{array}$ & $\begin{array}{c}\text { Mixed group } \\
(\mathrm{n}=49)\end{array}$ & $P$-value \\
\hline RSI & $14.1 \pm 5.4$ & $14.5 \pm 7.2$ & 0.733 \\
HRQOL & $66.9 \pm 44.0$ & $75.7 \pm 63.4$ & 0.457 \\
RFS & $10.4 \pm 3.0$ & $10.4 \pm 3.2$ & 0.960 \\
SF-12 (PCS) & $46.2 \pm 8.6$ & $41.4 \pm 9.1$ & $0.018^{*}$ \\
SF-12 (MCS) & $46.7 \pm 12.1$ & $45.0 \pm 10.2$ & 0.494
\end{tabular}

Values are presented as mean \pm standard deviation. RFS, reflux finding score; LPR, laryngopharyngeal reflux; RSI, reflux symptom index; HRQOL, health-related quality of life; SF-12, Short Form 12 Survey; PCS, physical component score; MCS, mental component score. ${ }^{*} P<0.05$. 
Table 2. Comparison of the DeMeester score and number of reflux events between nonacid and mixed LPR patients

\begin{tabular}{lccc}
\hline Variable & $\begin{array}{c}\text { Nonacid group } \\
(n=34)\end{array}$ & $\begin{array}{c}\text { Mixed group } \\
(n=49)\end{array}$ & $P$-value \\
\hline DeMeester score & $0.8 \pm 0.0$ & $1.2 \pm 1.1$ & $0.015^{*}$ \\
Distal reflux total & $9.1 \pm 11.1$ & $12.7 \pm 8.5$ & 0.103 \\
LPR total & $4.2 \pm 4.0$ & $9.0 \pm 8.7$ & $0.001^{*}$ \\
\hline
\end{tabular}

Values are presented as mean \pm standard deviation.

$L P R$, laryngopharyngeal reflux.

${ }^{*} P<0.05$.

nonacid reflux group than in the mixed reflux group $(P=0.001)$ (Table 2). Distal reflux events were also less frequent in the nonacid LPR group, but this was not significant $(P=0.134)$. The reflux symptoms association probability was not different between the two groups with regard to the symptom categories of cough and globus sensation (Table 3).

\section{DISCUSSION}

According to recent trends, PPIs are the first recommended choice for LPR management [15]. However, several cases are intractable to high-dose PPIs. If patients have severe symptoms and poor response to medication, surgical management by Nissen fundoplication can be considered, but it is not common [16]. Therefore, the authors focused on intractable LPR and investigated the characteristics of nonacidic LPR that was diagnosed with 24-hour MII monitoring [8,17].

Nonacid reflux disease is a newly understood type of GER that has been more easily identified using 24-hour MII pH monitoring. Due to its symptoms, which are refractory to PPI treatment and which manifest similarly to acid reflux disease, nonacid reflux disease has been considered to be an indistinguishable disease. However, now it can be studied to identify a cure for LPR [8].

Twenty-four-hour MII $\mathrm{pH}$ monitoring is a useful analytic and diagnostic instrument, and it has been widely used for the diagnosis of acidic or nonacidic GER since the 2000s. It can analyze the reflux contents (liquid, mixed, gas) and visualize the relations between laryngeal symptoms and reflux events, as well as the height of the reflux. These features were helpful for the diagnosis of nonacid reflux LPR, and we found that nonacid reflux LPR accounted for $41.0 \%$ of patients (34/83) in this study. Though it is difficult to directly compare this study to others, this study revealed a higher incidence of nonacid reflux than nonacid reflux GER; previous estimates were $20 \%$ to $30 \%$ [6,7].

While it is thought that airway inflammation and hypersensitivity are related to nonacid reflux, its pathophysiology can be explained by two major mechanisms. The reflex theory, also known as the esophago-tracheo-bronchial reflex theory, proposes that mucosal receptors are stimulated by reflux material, which then activates inflammatory mediators that cause extrae-
Table 3. Reflux symptoms association probability scores in nonacid and mixed LPR patients

\begin{tabular}{lccc}
\hline Variable & $\begin{array}{c}\text { Nonacid group } \\
(\mathrm{n}=34)\end{array}$ & $\begin{array}{c}\text { Mixed group } \\
(\mathrm{n}=49)\end{array}$ & $P$-value \\
\hline Cough $(\%)$ & $5.7 \pm 23.2$ & $9.2 \pm 26.0$ & 0.535 \\
Globus $(\%)$ & $8.4 \pm 27.6$ & $9.0 \pm 27.6$ & 0.925 \\
Heartburn (\%) & 0 & 0 & - \\
\hline
\end{tabular}

Values are presented as mean \pm standard deviation.

LPR, laryngopharyngeal reflux.

sophageal symptoms such as bronchial cough reflex or globus sensation. At the same time, corresponding efferent nerve endings release substance $\mathrm{P}$, calcitonin gene-related peptide, and other neuropeptides through exocytosis [18]. The proximal reflux or micro/macro-aspiration theory suggests that gastric contents back up in the throat due to structural and functional abnormalities in the lower esophagus [19]. Refluxate either directly stimulates cough receptors or increases mucus secretion through the vagal reflex, which activates the cough receptors and then causes laryngopharyngeal symptoms. Patterson et al. [19] found a high accumulation of nonacid refluxate in the proximal esophagus and hypopharynx in patients with nonacid GER with cough [20].

In this study, LPR was defined as proximal esophageal reflux. The nonacid reflux group showed up to $50 \%$ fewer LPR events than the mixed reflux group in contrast to previous literature [19]. Differences in study design, including diagnostic objectives, grouping methods, and study focus may have influenced the results. However, even though proximal reflux events were less common in the nonacid reflux group, the symptoms in both the nonacid reflux LPR group and the mixed reflux LPR group, as noted through the questionnaires, were similar. When we compared the physical component of SF-12 between the groups, the nonacid reflux group complained of more symptoms than the mixed acid reflux group did. Meanwhile, the authors have repeatedly evaluated the 24-hour MII $\mathrm{pH}$ monitoring results after each outbreak of symptoms, and there has been no single case report that showed a proximal $\mathrm{pH}<4$. Therefore, we were able to assume that pure acid reflux might not occur in LPR patients.

When treating nonacid LPR, it is necessary to provide alternative treatments in addition to empirical PPI administration. Although there are reliable studies of the mechanism and treatment of nonacid reflux, more research is necessary to help manage refractory LPR patients. This research should focus on pepsin or other neurotransmitters that can be activated by nonacidic stimuli. Also, because it is reported [18] that transient receptor potential vanilloid type I stimulates the vagus nerve to cause an esophago-tracheo-bronchial reflex, the authors think it would be helpful to identify the association between the autonomic nervous system and nonacid reflux to help advance diagnostic and therapeutic fields.

No LPR patient had only acid reflux. The nonacid reflux LPR 
patients showed similar clinical characteristics to patients in the mixed reflux group, but they experienced significantly fewer LPR events.

\section{CONFLICT OF INTEREST}

No potential conflict of interest relevant to this article was reported.

\section{ACKNOWLEDGMENTS}

This research was supported by the Bio \& Medical Technology Development Program of the National Research Foundation (NRF), and was funded by the Korean Government (MSIP\& MOHW) (NRF-2015M3A9E2029189), Republic of Korea.

\section{REFERENCES}

1. Koufman JA, Aviv JE, Casiano RR, Shaw GY. Laryngopharyngeal reflux: position statement of the committee on speech, voice, and swallowing disorders of the American Academy of OtolaryngologyHead and Neck Surgery. Otolaryngol Head Neck Surg. 2002 Jul;127 (1):32-5.

2. Hicks DM, Ours TM, Abelson TI, Vaezi MF, Richter JE. The prevalence of hypopharynx findings associated with gastroesophageal reflux in normal volunteers. JVoice. 2002 Dec;16(4):564-79.

3. Hoppo T, Sanz AF, Nason KS, Carroll TL, Rosen C, Normolle DP, et al. How much pharyngeal exposure is "normal"? Normative data for laryngopharyngeal reflux events using hypopharyngeal multichannel intraluminal impedance (HMII). J Gastrointest Surg. 2012 Jan;16(1):16-24.

4. Sifrim D, Castell D, Dent J, Kahrilas PJ. Gastro-oesophageal reflux monitoring: review and consensus report on detection and definitions of acid, non-acid, and gas reflux. Gut. 2004 Jul;53(7):1024-31.

5. Ford CN. Evaluation and management of laryngopharyngeal reflux. JAMA. 2005 Sep;294(12):1534-40.

6. Armstrong D, Pare P, Pericak D, Pyzyk M; Canadian Pantoprazole GERD Study Group. Symptom relief in gastroesophageal reflux disease: a randomized, controlled comparison of pantoprazole and nizatidine in a mixed patient population with erosive esophagitis or endoscopy-negative reflux disease. Am J Gastroenterol. 2001 Oct;96 (10):2849-57.
7. Meineche-Schmidt V, Juhl HH, Ostergaard JE, Luckow A, Hvenegaard A. Costs and efficacy of three different esomeprazole treatment strategies for long-term management of gastro-oesophageal reflux symptoms in primary care. Aliment Pharmacol Ther. 2004 Apr;19(8):907-15.

8. Storr MA. What is nonacid reflux disease? Can J Gastroenterol. 2011 Jan;25(1):35-8.

9. Belafsky PC, Postma GN, Koufman JA. The validity and reliability of the reflux finding score (RFS). Laryngoscope. 2001 Aug;111(8): 1313-7.

10. Ware J Jr, Kosinski M, Keller SD. A 12-Item Short-Form Health Survey: construction of scales and preliminary tests of reliability and validity. Med Care. 1996 Mar;34(3):220-33.

11. Carrau RL, Khidr A, Gold KF, Crawley JA, Hillson EM, Koufman JA, et al. Validation of a quality-of-life instrument for laryngopharyngeal reflux. Arch Otolaryngol Head Neck Surg. 2005 Apr;131 (4):315-20.

12. Belafsky PC, Postma GN, Koufman JA.Validity and reliability of the reflux symptom index (RSI). JVoice. 2002 Jun;16(2):274-7.

13. Lee BE, Kim GH, Ryu DY, Kim DU, Cheong JH, Lee DG, et al. Combined dual channel impedance/pH-metry in patients with suspected laryngopharyngeal reflux. J Neurogastroenterol Motil. 2010 Apr;16(2):157-65.

14. Potluri S, Friedenberg F, Parkman HP, Chang A, MacNeal R, Manus C, et al. Comparison of a salivary/sputum pepsin assay with 24hour esophageal $\mathrm{pH}$ monitoring for detection of gastric reflux into the proximal esophagus, oropharynx, and lung. Dig Dis Sci. 2003 Sep;48(9):1813-7.

15. Portnoy JE, Gregory ND, Cerulli CE, Hawkshaw MJ, Lurie D, Katz $\mathrm{PO}$, et al. Efficacy of super high dose proton pump inhibitor administration in refractory laryngopharyngeal reflux: a pilot study. $\mathrm{J}$ Voice. 2014 May;28(3):369-77.

16. Lee YS, Choi SH, Son YI, Park YH, Kim SY, Nam SY. Prospective, observational study using rabeprazole in 455 patients with laryngopharyngeal reflux disease. Eur Arch Otorhinolaryngol. 2011 Jun;268 (6):863-9.

17. Xu X, Yu L, Chen Q, Lv H, Qiu Z. Diagnosis and treatment of patients with nonacid gastroesophageal reflux-induced chronic cough. J Res Med Sci. 2015 Sep;20(9):885-92.

18. Niimi A, Torrego A, Nicholson AG, Cosio BG, Oates TB, Chung KF. Nature of airway inflammation and remodeling in chronic cough. J Allergy Clin Immunol. 2005 Sep;116(3):565-70.

19. Patterson N, Mainie I, Rafferty G, McGarvey L, Heaney L, Tutuian R, et al. Nonacid reflux episodes reaching the pharynx are important factors associated with cough. J Clin Gastroenterol. 2009 May-Jun; 43(5):414-9.

20. Oelschlager BK, Quiroga E, Isch JA, Cuenca-Abente F. Gastroesophageal and pharyngeal reflux detection using impedance and 24-hour $\mathrm{pH}$ monitoring in asymptomatic subjects: defining the normal environment. J Gastrointest Surg. 2006 Jan;10(1):54-62. 